\title{
Power Module Interconnection Reliability in BTS applications
}

\author{
Jussi Putaala, Juha Hagberg, Tero Kangasvieri, Juha Raumanni, Olli Salmela, Matti Rahko, Jussi \\ Jääskeläinen, Timo Galkin, Olli Nousiainen, Heli Jantunen
}

\begin{abstract}
In this article, the reliability of RF power transistors' solder attachments is characterized through experiments and simulations. Test cases consisted of power amplifier (PA) modules on AlSi10Mg substrates with either a low or high mutual thermal mismatch.

The module's flange interconnections were stressed by means of thermal cycling testing (TCT) in the $15{ }^{\circ} \mathrm{C}$ to $95{ }^{\circ} \mathrm{C}$ range. Scanning acoustic microscopy (SAM) was used intermittently to inspect the interconnections of selected structures during cycling breaks. Optical cross-polarization microscopy and scanning electron microscopy were used in the failure analysis of the solder joints.

Different materials and dimensional variations were tested in simulations to observe differences in thermal stress. The viscoplastic behavior of lead-free solder in the interconnection was modeled using Anand's constitutive equations.

The first cracks could be observed with SAM after 100 cycles. SAM imaging showed that in the worst case, $72 \%$ of the interconnection area had cracked at the end of the 1100-cycle TCT. Only a marginal amount of cracks could be observed in PA modules with a better CTE match to the substrate. Simulations indicated that it is possible to decrease creep energies significantly and thereby increase the lifetime expectancy of interconnections by selecting the correct materials and structures.
\end{abstract}

Index Terms-finite element analysis, power amplifier, reliability, solder joint.

\section{INTRODUCTION}

$\mathrm{T}$ HERMOMECHANICAL stresses in solder interconnections are among the most significant factors posing a risk of failure for modern power electronics assemblies. Besides structural and material choices, in critical systems it is a good idea to implement proactive diagnostics, i.e. prognostics, for the devices, to minimize system downtime often caused by failing interconnections [1-4].

In many applications, PA transistor modules are attached with solder to a baseplate typically made from silumin such as AlSi10Mg. Due to the mismatch of the coefficients of thermal expansion (CTE) of the materials, the solder is prone to cracking. As initiated cracks in PA modules often propagate in

Manuscript received December 10, 2018

J. Putaala (corresponding author), J. Hagberg, and H. Jantunen are with the Microelectronics Research Unit, University of Oulu, Finland.

T. Kangasvieri, J. Raumanni, M. Rahko, and J. Jääskeläinen are with Nokia, Oulu, Finland.

O. Salmela is with Nokia, Espoo, Finland. the interconnection between the module's flange and the baseplate, reduction of the interconnected area also reduces the amount of heat being able to be conducted away. As pointed out by Lutz et al., higher temperature leads to increasing power losses, therefore expediting degradation in a positive feedback loop [5]. To some extent this increase is compensated by a reduction of the distance to the neutral point due to the crack front being closer to it, therefore reducing thermomechanical forces. However, in power RF applications, stressing can result in degradation of the device's RF performance already during the early phase of crack propagation. This is noteworthy in applications that serve a large amount of users, such as in base transceiver stations (BTS) used in telecommunication networks.

Traditionally low CTE flange materials like $\mathrm{MoCu}$ has been used in PA modules because the power chip is directly attached to flange. During recent years power modules with pure $\mathrm{Cu}$ flanges have become commercially available. The motivation for this research is to compare the interconnection reliability of PA modules with these older and newer flange types. This is done by subjecting PA assemblies to thermal cycling tests (TCT) and characterizing them by using different imaging methods, including optical cross-polarization microscopy (OM), X-ray microscopy, scanning acoustic microscopy (SAM), and scanning electron microscopy (SEM). Besides physical inspections, the solder's response to induced stresses was studied by means of finite element models (FEMs). On the basis of FEM simulations, critical factors affecting the reliability of interconnections could be pointed out.

\section{EXPERIMENTAL SETUP \& PERFORMED SIMULATIONS}

\section{A. Test cases, thermal cycling tests (TCT), and inspections}

A sketch of the structure is shown in Figure 1. The PA module is attached to a cavity on the AlSi10Mg baseplate with a leadfree solder preformed for modules having either a $\mathrm{Cu}-\mathrm{MoCu}$ $\mathrm{Cu}$ (later denoted $\mathrm{CuMo}$ ) or a $\mathrm{Cu}$ flange, with $\mathrm{NiAu}$ (specified $\mathrm{Au}$ thickness $\max 2 \mu \mathrm{m}$ ) and $\mathrm{NiPdAu}$ (specified $\mathrm{PdAu}$ thickness $\max 0.12 \mu \mathrm{m}$ ) platings, respectively. The module consists of different parts pointed out in the figure; a lid protects

T. Galkin was with Nokia, Espoo, Finland. He is currently with Hyxo, Kerava, Finland.

O. Nousiainen is with the Materials and Mechanical Engineering Unit, University of Oulu, Finland.

Corresponding author: tel. +358-294-487-962; fax: $+358-8-553-2728$; email: jussi.putaala@oulu.fi.

Copyright @ 2019 IEEE. Personal use of this material is permitted. However, permission to use this material for any other purposes must be obtained by sending a request to pubs-permissions@iee.org 
the enclosed transistors from the outside environment. The transistors inside the module are attached on top of the flange. The main current flow is through two of the large component leads (drain connections) and the baseplate-flange interconnection (source connection).

The sample sets included PA modules having both $\mathrm{Cu}$ and CuMo flanges with a length of $32.2 \mathrm{~mm}$, width of $10.2 \mathrm{~mm}$, and thickness of around $1.7 \mathrm{~mm}$. The CuMo-flanged modules were attached to the baseplate with SAC305 solder, whereas the $\mathrm{Cu}$ flanged modules were attached with 96.3/3.7 $\mathrm{SnAg}$ solder. The samples were stressed in a thermal cycling test (TCT) chamber. The recommended TCT profiles are defined in the IPC-9701 and JEDEC JESD22-A104 standards, and the profile used for the current structures was adjusted on that basis $([6,7])$. The upper and lower peak temperatures of the TCT were set according to the expected conditions during device on/off operation. In particular, the set cycle profile was $15{ }^{\circ} \mathrm{C}$ to 95 ${ }^{\circ} \mathrm{C}$, with 10-minutes rise and fall times and 20 -minutes dwell times at the temperature extremes, resulting in one cycle per hour. The same profile was used in the simulations shown in Figure 2.

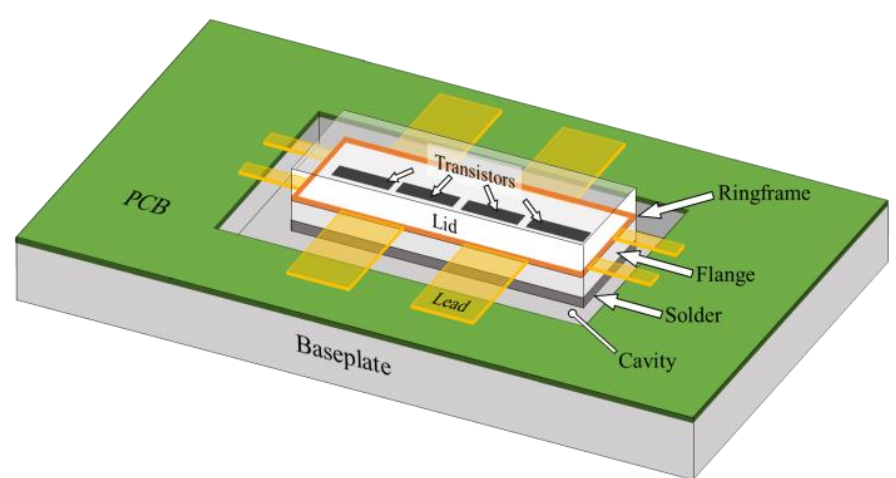

Figure 1. Sketch of the PA module on the baseplate (not to scale). The baseplate thickness was $5.8 \mathrm{~mm}$ and the cavity depth was $1.4 \mathrm{~mm}$.

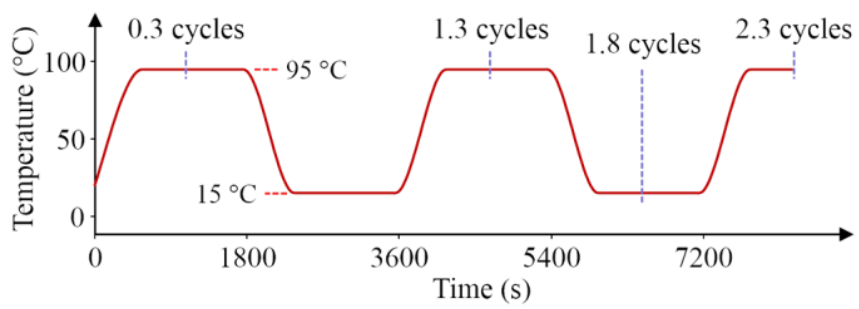

Figure 2. TCT profile used in the simulations, $15^{\circ} \mathrm{C}$ to $95^{\circ} \mathrm{C}$. The places of 0.3 , $1.3,1.8$, and 2.3 cycles are also shown for later reference.

The modules were imaged during cycling breaks and after TCT, before cross-sectional and fracture surface studies, using a Feinfocus FXS-160.23 X-ray microscope and a Sonoscan D9000 scanning acoustic microscope (SAM). C-type SAM images were produced with $50 \mathrm{MHz}$ and $100 \mathrm{MHz}$ focused transducers $\left(\mathrm{F}^{\#}=2\right)$ in a pulse-echo mode using the interface scan technique [8]. As there should be no air cavity between the SAM transducer and the imaged surface, the ceramic lids of the PA modules encasing the transistor chips had to be carefully removed. SAM inspections of selected samples were carried out after the lids of the PA modules were removed. Initial inspections were done before TCT, followed by intermittent inspections during cycling breaks. Intermittent inspections were done at 24, 50, 100, 200,300, 400, 500, 800, and 1100 cycles.

After TCT several samples were prepared for cross-sectional studies with optical microscopy and scanning electron microscopy/energy dispersive spectrometry (SEM/EDS). A dye and pry method was also used to observe the fractured areas. To analyze the chemical composition of two-phase $\mathrm{MoCu}$ in the $\mathrm{Cu}-\mathrm{MoCu}-\mathrm{Cu}$ flange, inductively coupled plasma-optical emission spectrometry (ICP-OES) analysis was performed.

\section{B. Simulation}

\section{1) Model development}

Figure 3 shows a cross-sectional sketch of the most likely place for crack initiation, i.e. the flange-baseplate solder interconnection at the edge of the flange and the related structures. The lamellar structure of the CuMo flange is also shown in the sketch.

The symmetry of the module and the configuration allowed a half-2D model to be used in the simulation, Figure 4 . The thermal elongation in the $\mathrm{x}$-direction, on the bottom and the outer end of the baseplate, was assumed to be independent of the solder layer and attached flange. This is because in the real structure, the flange has a finite width of only $10.2 \mathrm{~mm}$ and the baseplate continues perpendicularly to the $2 \mathrm{D}$ simulation plane (z-direction) in front of and behind the flange, which the 2D model does not take into account. In addition, the baseplate's higher thickness outside the cavity of the PA module assembly was not taken into account in the model, and is therefore less rigid than in reality.

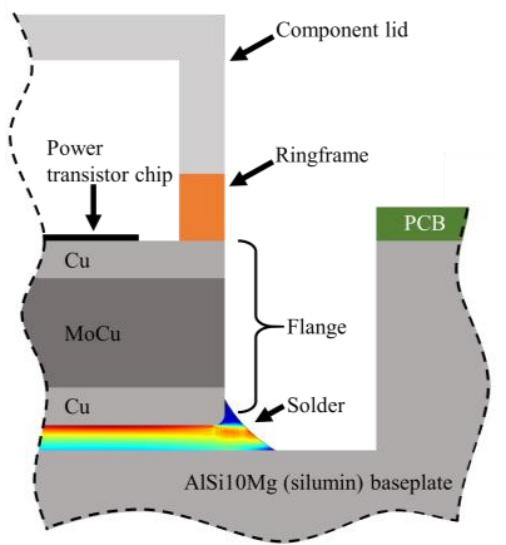

Figure 3. A sketched cross-sectional image of the PA module and its attachment to the baseplate (image not to scale). 


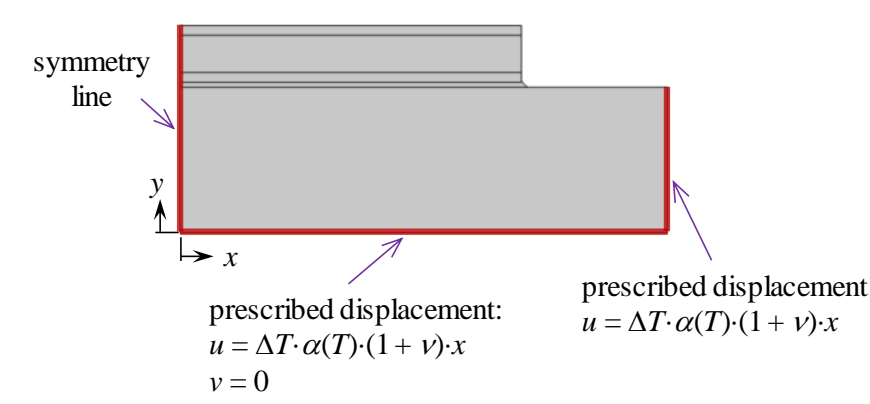

Figure 4. Half-2D model (short CuMo flange with a $150-\mu \mathrm{m}$-thick solder layer shown) with used boundary conditions.

$u=$ displacement in the $\mathrm{x}$-direction

$v=$ displacement in the $\mathrm{y}$-direction

$T=$ temperature

$\Delta T=$ temperature difference from the reference temperature $20^{\circ} \mathrm{C}$

$\alpha(T)=$ temperature-dependent CTE referenced to $20^{\circ} \mathrm{C}$

$v=$ Poisson's ratio

\section{2) Modeled structures}

Anand's constitutive model was used in the simulations [9]. The model accounts for the viscoplastic behavior of the solder material, including the strain rate and its history, temperature, and strain hardening/recovery effects. Thus, stress and inelastic strain in the model can be determined as a function of time. Further, the energy dissipated due to the inelastic strain (plastic work) can be calculated, which is the dissipated creep energy density.

The dissipated creep energy density was used to compare the simulated cases. Instead of using its localized and e.g. meshdependent maximum value, an averaged value was used. After running each FEM model, the creep energy density average per cycle over a cross-sectional area of $3600 \mu \mathrm{m}^{2}$ (corresponding to, for example, the area of a square sized $60 \times 60 \mu \mathrm{m}^{2}$ ) containing the maximum creep energy was determined. Later this energy is denoted as the representative creep energy, $W_{\text {rce }}$, and is used to compare thermal stress effects of different modeled structural constructions.

The varied parameters in the evaluated Comsol Multiphysics ${ }^{\circledR}$ models were:

- $\quad$ Flange materials

- $\mathrm{Cu}-\mathrm{MoCu}-\mathrm{Cu}(\mathrm{CuMo})$ lamellar composition

- $\mathrm{Cu}$, with a better CTE match to the AlSi10Mg baseplate material than the CuMo

- Short and long PA modules

- The flange length was varied as a geometric series from $13.16 \mathrm{~mm}$ to $50.50 \mathrm{~mm}$ with seven steps. The nominal flange lengths of typical PA modules are between these extremes, 20.6 $\mathrm{mm}$ and $32.3 \mathrm{~mm}$, which are later referred to as short and long flanges, respectively. Similarly, modules with a short or long flange are later referred to as short and long modules, respectively.

- Solder thicknesses

- Four thicknesses of the solder layer between the module's flange and the baseplate were used in simulations: $56 \mu \mathrm{m}, 90 \mu \mathrm{m}, 150 \mu \mathrm{m}$, and $250 \mu \mathrm{m}$.

- A special case was run in which the solder thickness was varied as a geometric series from $43 \mu \mathrm{m}$ to $323 \mu \mathrm{m}$ with nine thicknesses. This was done in order to observe the effect of solder thickness in creep energies in greater detail.

- Solder type

○ Models with a CuMo flange were simulated with SAC305 solder Anand parameters.

- Models with a $\mathrm{Cu}$ flange were simulated with SnAg solder Anand parameters and, for comparison, same simulations were made with SAC305 solder Anand parameters.

\section{3) Material parameters}

Material parameters were taken either from literature or from the material library of the simulation software. The component's lid material and silicon chip, as well as the baseplate's PCB, were assumed to have only a minor effect on the stresses between flange and baseplate, so they were left out of the simulations.

Material parameters for the SAC305 Anand model were taken from Figure 25 in [10], with an aging time of $120 \mathrm{~h}$ at 100 ${ }^{\circ} \mathrm{C}$. This was selected because the aging effect takes place also during thermal cycling. For the SnAg solder, the Anand parameters of SnAg 96.5/3.5 from [11] were adopted, being the closest composition of the actually used SnAg 96.3/3.7, found in the literature.

The chemical composition of $\mathrm{MoCu}$ in the $\mathrm{Cu}-\mathrm{MoCu}-\mathrm{Cu}$ flange was found to be $30 \% \mathrm{Cu}$ and $70 \% \mathrm{Mo}$ (by weight) as reported in the results section. The needed material parameters for FEM modeling were taken from a material manufacturer [12], except for Poisson's ratio the one for Molybdenum was used.

The rest of the material parameters with their corresponding temperature dependencies are embedded in the simulation software's library, which was used. The key material parameters at room temperature $\left(20^{\circ} \mathrm{C}\right)$ are listed in Table I (CTE referenced to $20^{\circ} \mathrm{C}$ ).

TABLE I

MATERIAL PARAMETERS AT $20^{\circ} \mathrm{C}$ TEMPERATURE TAKEN FROM SIMULATION

\begin{tabular}{lcccc}
\hline Material & $\begin{array}{c}\mathrm{CTE} \\
\mathrm{ppm} /{ }^{\circ} \mathrm{C}\end{array}$ & $\begin{array}{c}\text { Density } \\
\mathrm{kg} / \mathrm{m}^{3}\end{array}$ & $\begin{array}{c}\text { Young's } \\
\text { modulus } \\
\mathrm{GPa}\end{array}$ & $\begin{array}{c}\text { Poisson's } \\
\text { ratio } \\
\text { (unitless) }\end{array}$ \\
$\begin{array}{l}\text { Module's flange: } \\
\bullet \mathrm{MoCu}\end{array}$ & 7.5 & 9600 & 220 & 0.37 \\
$\quad \cdot \mathrm{Cu}$ & 16.7 & 8950 & 126 & 0.34 \\
SAC305 solder & 21.5 & 7360 & 51.2 & 0.35 \\
AlSi10Mg baseplate & 21.1 & 2630 & 71.1 & 0.33 \\
\hline
\end{tabular}

\section{RESULTS}

\section{A. Microscopy imaging and analysis}

SAM images of the flange attachment together with an X-ray reference image at the top are shown in Figure 5a and b. Note 
that the bottom side images have been mirrored to enable a better comparison with the top side images. Cracks observed in the SAM images are indicated with yellow lines. The earliest fractures observed with SAM occurred after 100 cycles. In the worst case for a CuMo flange, the cracked area was $72 \%$ of the total flange interconnection area at the end of the test (1100 cycles). A single crack observed with SAM in the solder interconnection of modules with a $\mathrm{Cu}$ flange is pointed out in Figure 5b, which also shows huge voids that were not observed in any other sample. No other cracks were observed in any SAM images of $\mathrm{Cu}-\mathrm{flanged}$ cases.
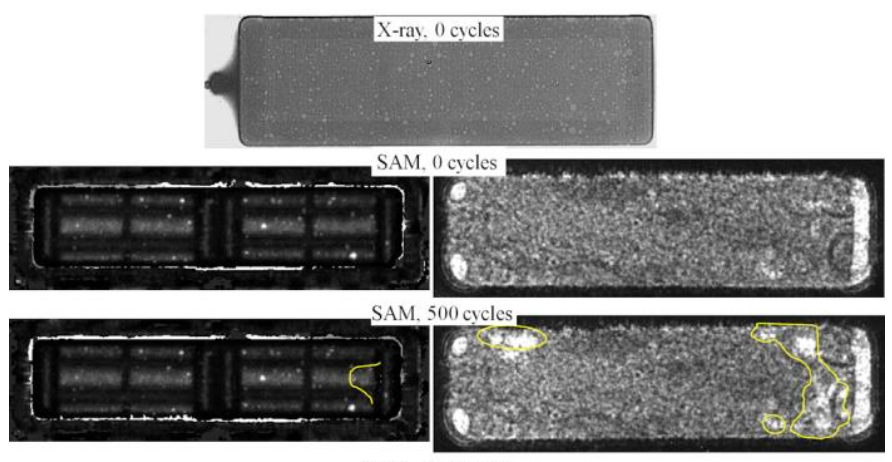

SAM. 1100 crcles

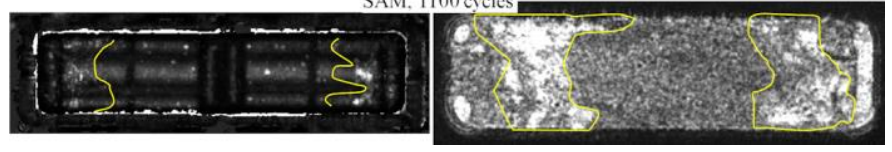

a)

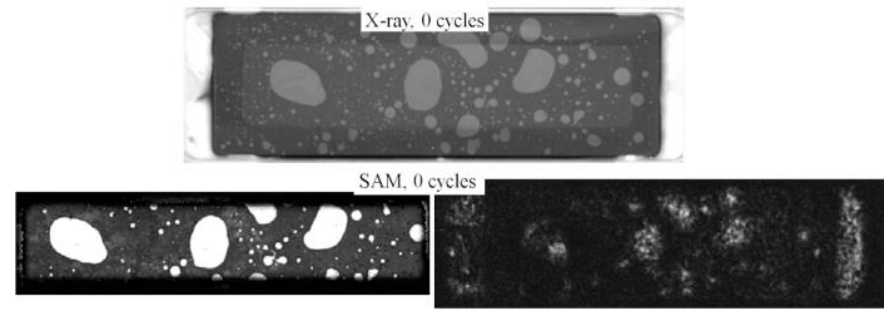

SAM, 500 cycles 0

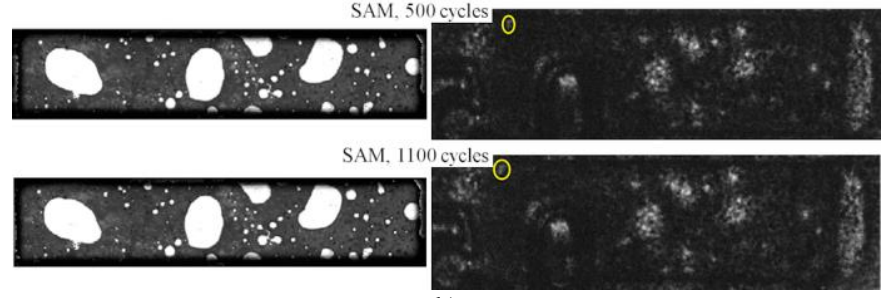

b)

Figure 5. Images of stressed samples after different amounts of thermal cycles; observed crack locations are marked in the images. a) Sample with a CuMo flange, b) Sample with a $\mathrm{Cu}$ flange. An X-ray image of each sample, taken before TCT, is at the top, whereas SAM images of the PA modules' solder layers imaged from the top and bottom sides are on the left and right sides, respectively.

Figure 6 shows solder remaining on the substrate cavity after detaching the module. On the left side of the image flat prying mark can be seen; there is loose material near the middle area of the module that was removed from the sample during prying and landed there. In this image the yellow lines represent the same area of observed cracks in SAM imaging, confer to Figure 5a, right hand side image after 1100 cycles.

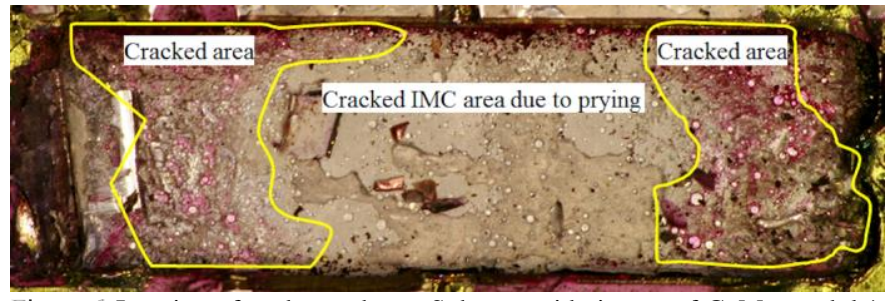

Figure 6. Imaging after dye and pry. Substrate side image of CuMo module's solder area, cf. Figure 5a.

As to modules with a $\mathrm{Cu}$ flange, only a small initiated crack at the edge of the component's interconnection was observed in SAM imaging through the bottom side. Dye and pry revealed cracks at the edges of the $\mathrm{Cu}$ flange, under the ring frame. However, the amount in the worst case was $8.5 \%$ of the total interconnection area. An initially observed cavity, i.e., one not related to cracking, is also included in this percentage.

Comparing cracked areas evaluated from SAM images to those obtained from dye and pry, it was observed that SAM from top side gives a similar or slightly smaller amount of cracked area. On bottom side the evaluated cracked areas in SAM images was generally smaller.

The thickness of the flange measured from the cross-sections averaged $1710 \mu \mathrm{m}$, and for a CuMo flange, the partial thicknesses of $\mathrm{Cu}$ and $\mathrm{MoCu}$ were $290 \mu \mathrm{m}$ and $1130 \mu \mathrm{m}$, respectively. According to the ICP-OES analysis, the $\mathrm{MoCu}$ consisted of $30 \% \mathrm{Cu}$ and $70 \%$ Mo by weight. The baseplate thickness under the module was $4.4 \mathrm{~mm}$. These measurements were used in the simulations. The solder thickness varied from 150 to $280 \mu \mathrm{m}$.

\section{B. Metallographic investigation}

The cross-sections of the specimens were investigated using cross-polarized optical microscopy. In the case of the $\mathrm{Cu}$ flange, the initial dendritic solidification structure remains after TCT, Figure 7a. Thus, no recrystallization occurred in the SnAg solder joint. Contrary to this, in the case of the CuMo flange the SAC solder joint recrystallized fully in the TCT, Figure $7 \mathrm{~b}$. From the closeup image of this area, microvoids and grain boundary cracking can be detected (Figure 7c). This type of failure formation is typical for the creep failure of a ductile metal alloy. 


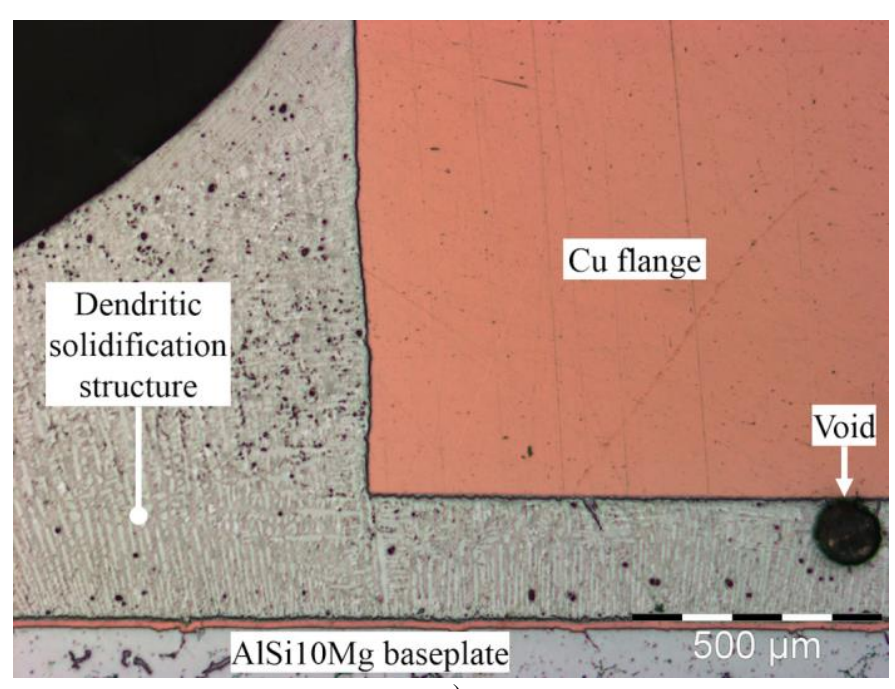

a)

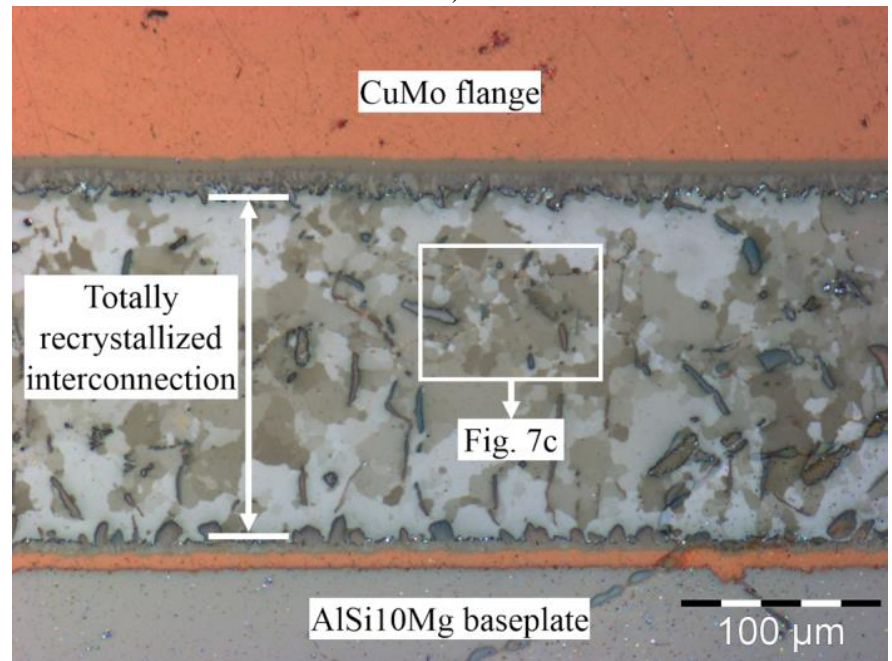

b)

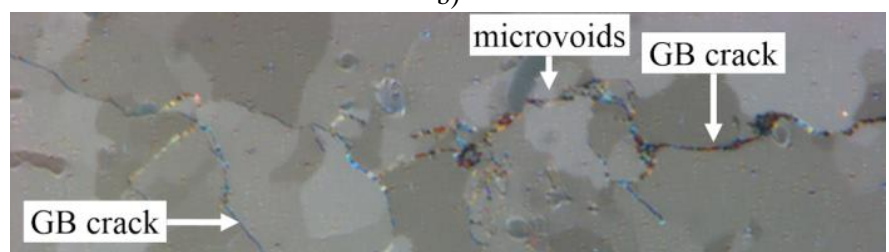

$20 \mu \mathrm{m}$

c)

Figure 7. Optical images of a) dendritic solidification structure of SnAg solder after TCT, b) fully recrystallized SAC solder joint between CuMo flange and baseplate, and c) formed microvoids and grain boundary (GB) cracks due to the creep of the recrystallized SAC solder, imaged area pointed out in (b).

In order to characterize the microstructure of the solder joints, SEM/EDS investigation were conducted. It was observed that the microstructure of near eutectic $\mathrm{Sn} 3.7 \mathrm{Ag}$ solder has a typical near eutectic microstructure with dispersion free primary tin and eutectic $\mathrm{Sn} / \mathrm{Ag}_{3} \mathrm{Sn}$ areas, as shown in Figure 8. Naturally, the cooling rate have a significant effect on the size and distribution of the IMC particles and tin phase, but generally speaking this type of microstructure is typical for near eutectic tin-based solder alloys with silver assuming that the tin is the primarily solidified phase.

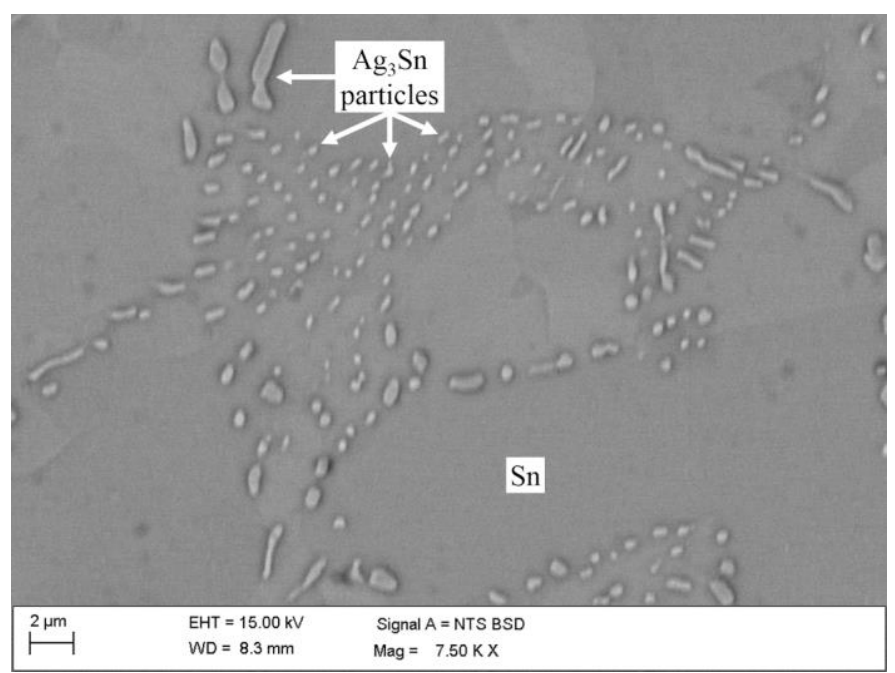

Figure 8. SEM image of the microstructure of $\mathrm{SnAg}$ solder in $\mathrm{Cu}$ flange specimen: Fine $\mathrm{Ag}_{3} \mathrm{Sn}$ particles within $\mathrm{Sn}$ matrix.

On the contrary, the SAC solder had an unanticipated microstructure. Typical Au thickness in ENIG coating is 3-4X than Au in NiPdAu (40-60 nm). The ENIG surface of the flange contained thicker amount of $\mathrm{Au}$ that caused rather unique microstructure in these joints. First of all, relatively long $(<100$ microns) lamellar $\mathrm{AuSn}_{4}$ particles formed within the solder bead, as shown in Figure 9a. In the critical area, the shape of these IMCs is more equiaxed or rod like (Figure 9b). Moreover, the $\mathrm{Ag}_{3} \mathrm{Sn}$ particle size and distribution is quite different comparing the typical microstructure the SAC305 solder. There are no typical eutectic $\mathrm{Sn} / \mathrm{Ag}_{3} \mathrm{Sn}$ areas with fine particle size, but the $\mathrm{Ag}_{3} \mathrm{Sn}$ particles are relatively large, up to 10 microns, and unevenly distributed, as shown in Figure 9. Similarly, the $\mathrm{Cu}_{6} \mathrm{Sn}_{5}$ type intermetallic compounds $\left(\left(\mathrm{Cu}, \mathrm{Ni}_{6} \mathrm{Sn}_{5}\right)\right.$ have grown large round particles.

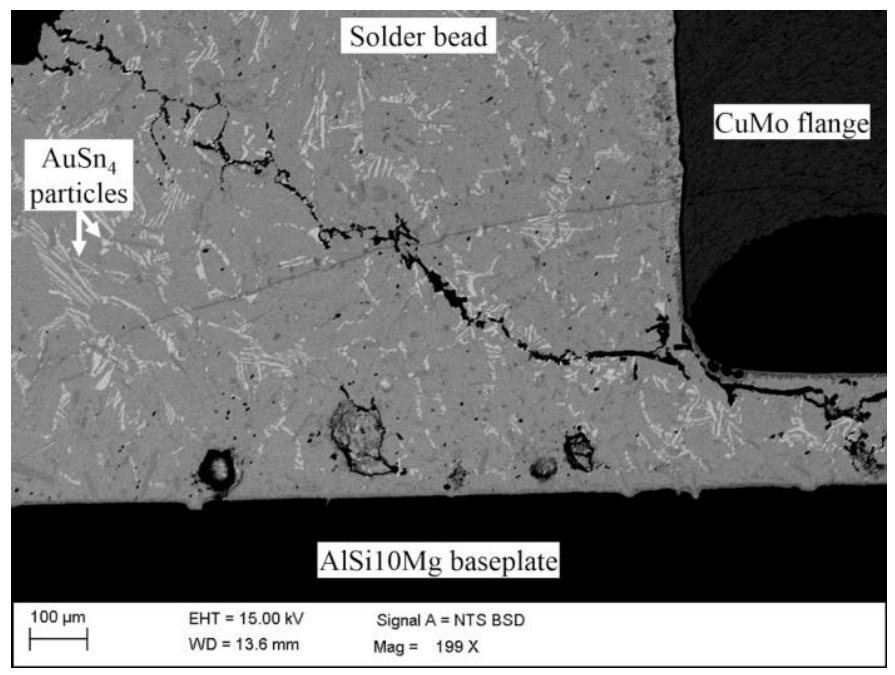

Copyright @ 2019 IEEE. Personal use of this material is permitted. However, permission to use this material for any other purposes must be obtained by sending a request to pubs-permissions@ieee.org 
a)

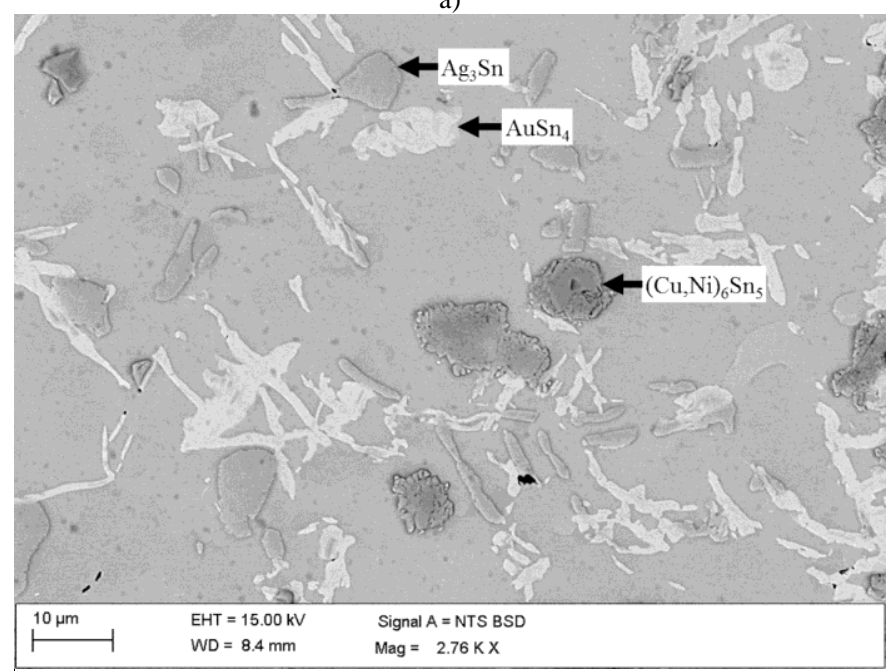

b)

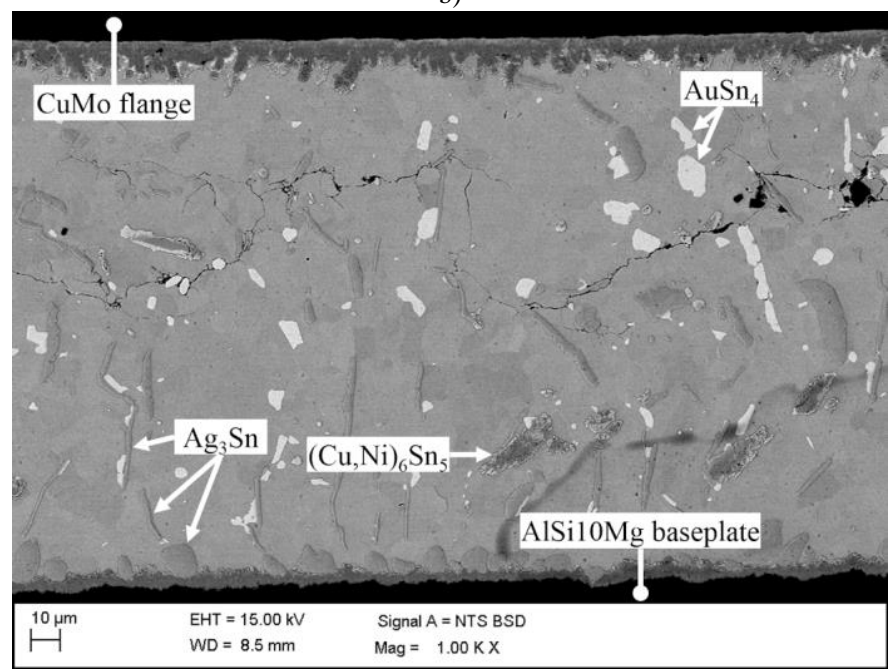

c)

Figure 9. Backscattered SEM images of a) final crack path and lamellar AuSn4 intermetallic particles, b) $\mathrm{Ag}_{3} \mathrm{Sn}, \mathrm{AuSn}_{4}$ and $\mathrm{Cu}_{6} \mathrm{Sn}_{5}$ particles within tin matrix, and c) the particle distribution and intergranular creep cracks between $\mathrm{CuMo}$ flange and baseplate.

Another significant difference between the test specimens was the voiding. Voids themselves present an easy fracture path for a propagating crack, but they also concentrate stresses in their vicinity. This results in more severe strain and the formation of a recrystallized area $[13,14]$. This behavior was also observed in SnAg joints, as shown in Figure 10. However, the creep failure did not form in these areas during the TCT.

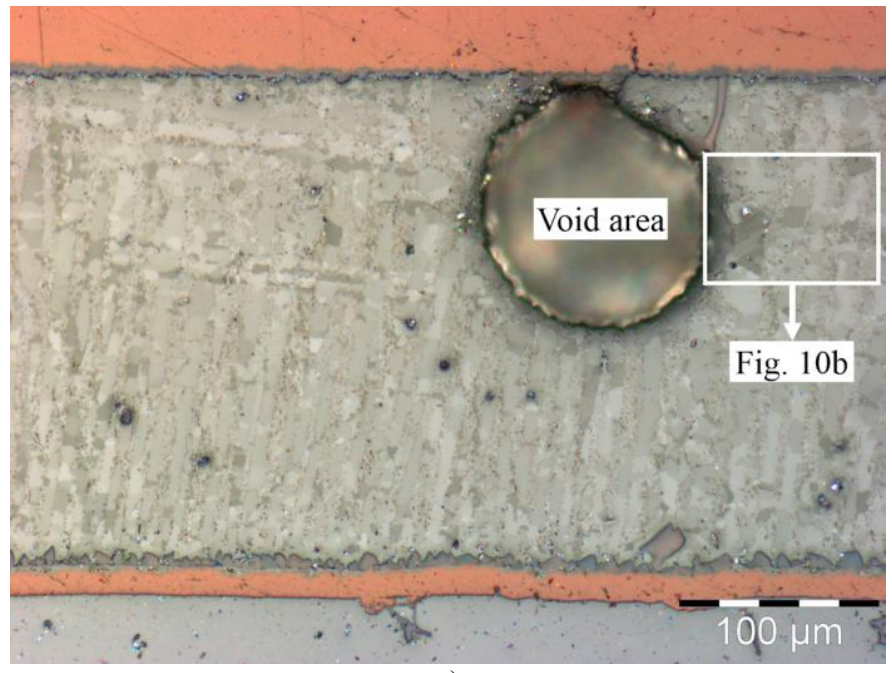

a)

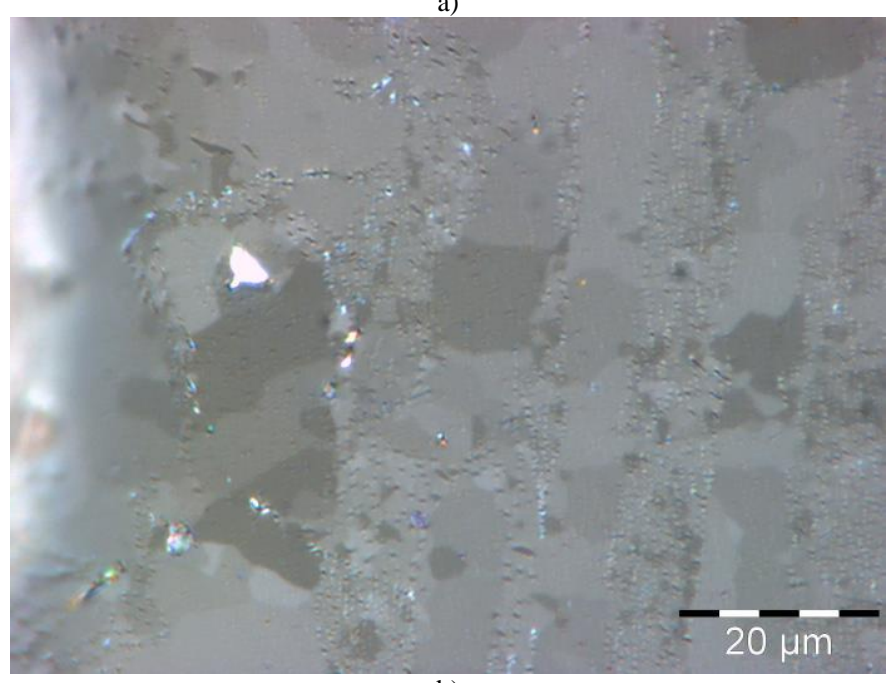

b)

Figure 10. Optical image of a) a void in the SnAg solder and b) the recrystallized grains in the vicinity of the void, imaged area pointed out in (a).

\section{Simulation}

If not otherwise stated, all the following simulation results presented are for CuMo and $\mathrm{Cu}$ flanges with SAC305 and SnAg solder Anand parameters in models, respectively.

Figure 11 shows simulated average creep energy densities for different solder layer thicknesses as a function of time for 2.3 cycles, compare with Figure 2. These initially run simulations indicated that creep energy per cycle stabilized after a few cycles. Therefore, the models did not need to be simulated for a large amount of cycles.

Copyright (C) 2019 IEEE. Personal use of this material is permitted. However, permission to use this material for any other purposes must be obtained by sending a request to pubs-permissions@iee..org 


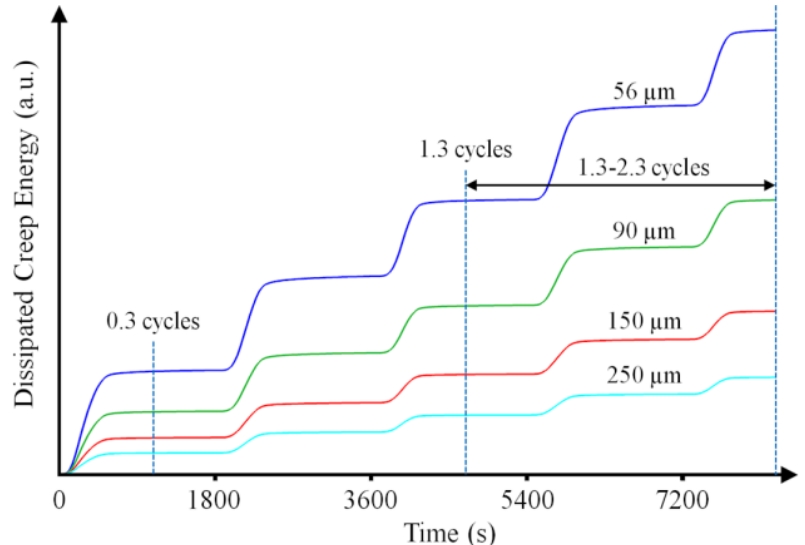

Figure 11. 2D-simulated average creep energy within the solder layer of a long CuMo flange as a function of time for 2.3 cycles ( $3600 \mathrm{~s}$ corresponds to one cycle). The results are presented for the four solder thicknesses shown.

For representative creep energy analysis for each case, a whole cycle between 1.3 and 2.3 cycles, corresponding to 4680 and 8280 seconds, was selected (from hot to hot, see Figure 2).

In Figure 12 a) and b) the evaluated representative creep energies, $W_{\text {rce }}$, are shown for different solder thicknesses as a function of flange length for $\mathrm{CuMo}$ and $\mathrm{Cu}$ flanges, respectively. In addition to using $\mathrm{SnAg}$ Anand parameters (unbroken lines), a $\mathrm{Cu}$ flange was simulated with SAC305 parameters (broken lines) for solder thicknesses of $56 \mu \mathrm{m}$ and $250 \mu \mathrm{m}$. To illustrate the difference in energy scales for these two flange materials, the uppermost curve in Figure $12 \mathrm{~b}$ ) is also shown in Figure 12 a), being the lowermost one (broken orange line with square marks). The place of the highest $W_{r c e}$ in all cases was just under the flange in the vicinity of its outer end, i.e. farthest away from the neutral point.

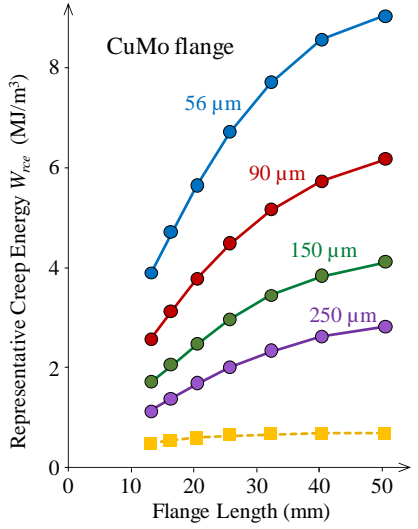

a)

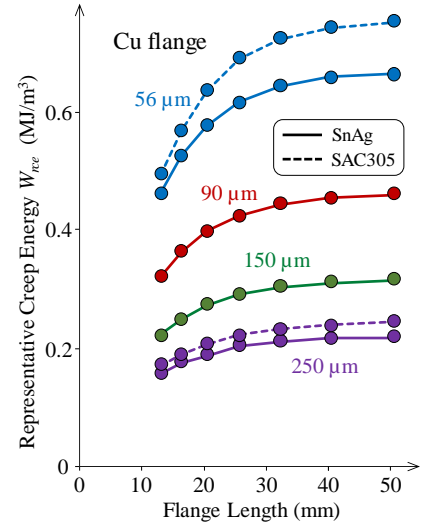

b)
Figure 12. Representative creep energy $W_{\text {rce }}$ as a function of flange length for a) $\mathrm{CuMo}$ and b) $\mathrm{Cu}$ flanges for different solder thicknesses. In addition to using $\mathrm{SnAg}$ Anand parameters (unbroken lines) a $\mathrm{Cu}$ flange was simulated with SAC305 parameters (broken lines in figure b)) for solder thicknesses of $56 \mu \mathrm{m}$ and $250 \mu \mathrm{m}$. To illustrate the difference in energy scales, the uppermost curve in Figure b) is also shown in Figure a), being the lowermost one.

Figure 13 shows of how the shear stress behaves between baseplate and a) a $\mathrm{CuMo}$ and b) a $\mathrm{Cu}$ flange when the temperature changes from the cold end to the hot end (from 15 ${ }^{\circ} \mathrm{C}$ to $95{ }^{\circ} \mathrm{C}$ in 10 minutes) during the second simulated cycle for long flange. In both Figure 13a) and b), the uppermost blue line represents the shear stress just before the temperature starts to increase after staying at the cold end.

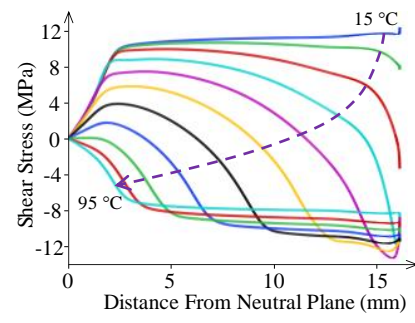

a)

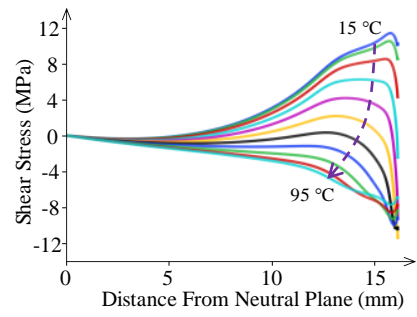

b)
Figure 13. Shear stress between baseplate and flange as a function of the distance from the neutral plane, when the temperature changes from the cold end to the hot end (from $15{ }^{\circ} \mathrm{C}$ to $95^{\circ} \mathrm{C}$ in $10 \mathrm{~min}$ ) during the second simulated step for a) CuMo and b) Cu flange. With a solder thickness of $150 \mu \mathrm{m}$ and with long flange. The temperature (and time) increase in the direction of the broken arrow line.

Figure 14 shows the 2D-simulated shear stress between the baseplate and a) a CuMo and b) a Cu flange at the temperature's cold and hot ends (after 1.8 and 2.3 cycles) with varying flange lengths.

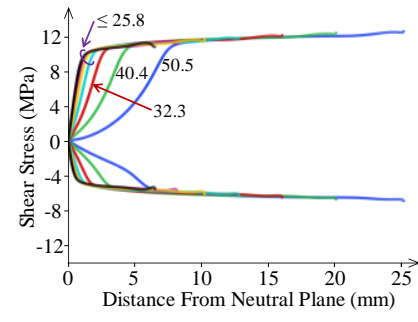

a)

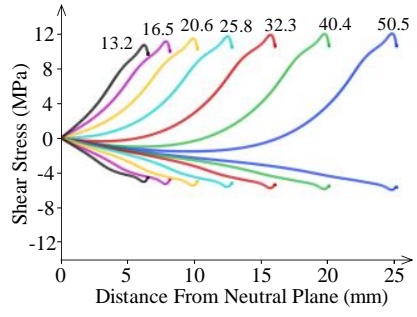

b)
Figure 14. 2D-simulated shear stress between the baseplate and a) a CuMo flange and b) a Cu flange, at the temperature's cold and hot ends (after 1.8 and 2.3 cycles corresponding to an 8 -min dwell time after the preceding ramp) with different flange lengths as a function of the distance from the neutral plane. A solder thickness of $150 \mu \mathrm{m}$ was used in simulations. The numbers close to each line represents the flange length in $\mathrm{mm}$. The color code in both figures is the same.

The results presented in Figure 13 and Figure 14 are both simulated with a solder thickness of $150 \mu \mathrm{m}$. Varying the solder thickness had only a minor effect on the behavior of the residual shear stress. Thinner solder gives somewhat bigger stress levels.

To simulate the effect of solder thickness on $W_{\text {rce }}$, it was varied as a geometric series from $43 \mu \mathrm{m}$ to $323 \mu \mathrm{m}$ with nine steps. The selected test case was a long PA module with both $\mathrm{CuMo}$ and $\mathrm{Cu}$ flange materials, Figure 15. An inverse, nonlinear relationship between $W_{\text {rce }}$ and solder layer thickness is seen. Power law equations show the best fits for the data.

Copyright $\odot 2019$ IEEE. Personal use of this material is permitted. However, permission to use this material for any other purposes must be obtained by sending a request to pubs-permissions@ieee.org 


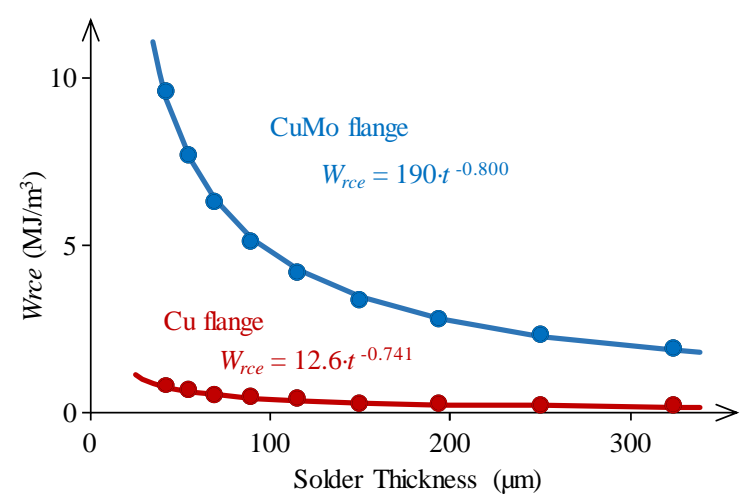

Figure 15. Representative creep energy $W_{\text {rce }}$ as a function of solder thickness for a long PA module with $\mathrm{CuMo}$ and $\mathrm{Cu}$ flanges. Power law fits and equations are shown. Equations give $W_{\text {rce }}$ in $\mathrm{MJ} / \mathrm{m}^{3}, t=$ solder layer thickness in $\mu \mathrm{m}$.

\section{DISCUSSION}

\section{A. TCT and inspections}

The TCT range was severe enough to induce cracking in the solder, especially in assemblies made with a CuMo flange. Cracking is also likely to occur in the field within a reasonable time.

The flange's uneven top face, carrying power transistor chips, caused ghosting in the SAM images of the solder layer taken through this interface, as seen in Figure 5, left side images. On the top side also the ring frame of the module hindered imaging from underneath the layer, which resulted in earlier observation of cracks through the bottom side in several occasions. This is because cracks initially appear in the areas of greatest stress, which are usually located in the corner regions of module interconnections. However, the non-homogeneous structure of the baseplate caused graininess in the images taken from the bottom i.e. the baseplate side (Figure 5, right side images). Discerning the cracks and their propagation required contrasting to images previously taken from the same sample.

Still, crack propagation could be observed in the structures relatively easily for $\mathrm{CuMo}$ flanges, as seen in Figure 5a. Compared with the initial situation ( 0 cycles), the images taken after 500 cycles show cracks on both the top and bottom sides, indicated with yellow lines. The effective solder area in the imaged interface was reduced considerably after 1100 cycles. The bottom side images have been mirrored to better enable contrasting to the top side images. Interconnection cracking observed in the modules with a $\mathrm{Cu}$ flange was marginal compared with those with a CuMo flange. In the only case where cracking was observed with SAM, the cracked area was minimal, despite a large amount of voids in the particular interconnection. That is, thermal mismatch and effective Young's moduli are clearly smaller with a $\mathrm{Cu}$ flange, resulting in a reduced amount of cracks during TCT. This is also confirmed by simulations, in which $W_{\text {rce }}$ values were found to be more than a decade smaller for modules with a $\mathrm{Cu}$ flange compared with those of modules with a CuMo flange.

The cracks had propagated along the $\mathrm{AuSn}_{4}$ and bulk solder interfaces, which is a phenomenon observed often before [15]. The rigidity of the module, especially like that with a
CuMo flange, caused the cracks to propagate generally closer to the module than the baseplate.

\section{B. Failure analysis of solder joints}

Generally, the as-soldered tin based lead-free solders joints consist of a few large Sn grains where intermetallic compounds (IMC), like $\mathrm{Ag}_{3} \mathrm{Sn}$ particles, are embedded [13, 16-21]. It is also a well-known fact that recrystallization occurs in thermomechanically loaded joints of these solder alloys during the typical thermal cycling tests. Furthermore, the primary intergranular crack propagates along the recrystallized zone [13, 19-21].

On the other hand, the observation shown in Figure 7a proved that the $\mathrm{SnAg}$ solder joint can resist the inelastic deformation enough in order to avoid recrystallization. This is consistent with the findings of the other studies. For example, no clear evidence of recrystallization in $\mathrm{Sn} 3.8 \mathrm{Ag} 0.7 \mathrm{Cu}$ fatigue specimens was detected in the isothermal cycling tests at various temperatures [22,23]. Similarly, no occurrence of recrystallization in a $\mathrm{SnAgCu}$ alloy was observed in thermal cycling test of lap joint specimens at various temperatures or in thermal cycling testing (TCT) over a temperature range of RT $100{ }^{\circ} \mathrm{C}[24,25]$.

Moreover, Hokka et al. [26, 27] showed that in real use conditions no recrystallization was observed in the solder joints of relatively large $(12 \mathrm{~mm} \times 12 \mathrm{~mm}) 144$ BGA joints. In their studies, they pointed out that the correspondence of microstructural changes and failure mechanism between the non-accelerated and accelerated interconnections should be taken into account in the lifetime prediction models and simulations. Finally, it was proved that the effect of global thermal mismatch between component and the substrate has a major effect on the recrystallization behavior of different tin based lead-free solders [28-30].

Since the global thermal mismatch of the $\mathrm{Cu}$ flange and baseplate was small, about $5 \mathrm{ppm} /{ }^{\circ} \mathrm{C}$, and the TCT range relatively mild, the observed excellent creep resistance of $\mathrm{SnAg}$ solder is quite reasonable. Even the local strain concentration and the formation of a recrystallized area in the vicinity of the voids did not cause a creep failure in these joints (Figure 10).

The SAC solder was fully recrystallized between the CuMo flange and baseplate (Figure 7b). The SAM investigation also proved that the failure initiated and propagated in this area. Naturally, the extremely large global thermal mismatch (18 $\mathrm{ppm} /{ }^{\circ} \mathrm{C}$ ) of the CuMo flange/baseplate configuration makes these solder joints prone to recrystallization. But one should also take the effect of the microstructure in account when the creep resistance of the material is estimated.

Considering the effect of the microstructure on the recrystallization process of the lead-free solder joints, it was shown that relatively high ( $x \geq 3 \mathrm{wt} \%) \mathrm{Ag}$ content resulted in suppressed grain growth in the recrystallized $\mathrm{SnxAg} 0.5 \mathrm{Cu}$ solder matrix during the TCT over a temperature range of -40 ${ }^{\circ} \mathrm{C}$ to $125{ }^{\circ} \mathrm{C}$ compared with the low $(\leq 2 \mathrm{wt} \%) \mathrm{Ag}$ content. It was assumed that the pinning effect of fine $\mathrm{Ag}_{3} \mathrm{Sn}$ dispersions resulted in suppressed grain growth in SAC alloys [13, 31, 32]. Moreover, Sundelin et al. [13] showed that the hypoeutectic $\mathrm{Sn} 3 \mathrm{Ag} 0.5 \mathrm{Cu}$ solder recrystallized more readily than the 
$\mathrm{Sn} 3.8 \mathrm{Ag} 0.7 \mathrm{Cu}$ and $\mathrm{Sn} 4 \mathrm{Ag} 0.5 \mathrm{Cu}$ solders. They concluded that this difference was related to the lower amount of $\mathrm{Ag}_{3} \mathrm{Sn}$ particles in the hypoeutectic solder. Thus, the Ag-content seems to have a major effect on the solidified microstructure.

Assuming that the eutectic composition of SnAg binary alloy is $\mathrm{Sn} 3.5 \mathrm{Ag}$ ([33]), the first phase to solidify in equilibrium conditions is $\mathrm{Ag}_{3} \mathrm{Sn}$. However, the SEM investigation showed (Figure 8) that the near eutectic $\mathrm{Sn3} .7 \mathrm{Ag}$ solder has a microstructure with dispersion-free primary tin and eutectic $\mathrm{Sn} / \mathrm{Ag}_{3} \mathrm{Sn}$ areas. These dispersion-free areas are more prone to the accumulation of inelastic strain and the subsequent recrystallization and creep failure compared with the microstructure of eutectic alloys with fine $\mathrm{Ag}_{3} \mathrm{Sn}$ particles and their distribution within the tin matrix [13,32]. There are two possible explanations for this behavior. Firstly, the composition of the melt was not eutectic. In this case, either the actual silver content was lower than the nominal content and/or the extra solute atoms from NiPdAu metallization of the flange changed the solidification sequences of the melt. Another reason is the non-equilibrium conditions during the solidification of the joints, which together with the off-eutectic composition of melt have resulted in the formation of the dendritic solidification structure shown in Figure 7a.

As shown in Figure 9, the SAC solder had an unexpected microstructure with long lamellar $\mathrm{AuSn}_{4}$ particles formed within the solder bead. The shape of these particles was more equiaxed or rod like in the critical area between the flange and the baseplate. The $\mathrm{Ag}_{3} \mathrm{Sn}$ particle size and distribution was also quite different compared to the typical microstructure of the SAC305 solder (Figure 9). The authors believe that the formation of these coarse $\mathrm{Ag}_{3} \mathrm{Sn}$ particles instead of the typical fine particle size was due to the increased temperature range between liquidus and solidus of the Au containing SAC melt and the off-eutectic solidification sequences of this particular Au containing SAC alloy.

However, it can be noted from Figure 7c and Figure 9c, that the IMC particles within the critical area did not have any major contribution to the creep failure formation, but the main reason for the failure is the formation of the recrystallized area and the subsequent creep cracking. The IMC particle size was relatively large and distribution was too sparse in order to cause any notable precipitation hardening. Theoretically speaking, this coarse microstructure has an adverse effect to the recrystallization behavior since there is no sufficient precipitate structure to hinder dislocation movement during a thermal cycle. Thus, the accumulation of the inelastic deformation is faster and the recrystallization occurs earlier compared to the microstructure with the typical fine $\mathrm{Ag}_{3} \mathrm{Sn}$ particle distribution. The primary crack path was therefore formed in the grain boundaries and the crack propagated along the IMC/tin phase boundary only occasionally.

On the basis of the above discussion it was concluded that the better resistance of $\mathrm{Cu}$ flange with $\mathrm{SnAg}$ solder was due to a low global thermal mismatch and stable as-soldered microstructure, whereas the extremely large global thermal mismatch between CuMo flange and the baseplate and the adverse off-eutectic as-soldered microstructure of the SAC solder joints make them prone to recrystallization in the present test conditions. After the formation of a recrystallized microstructure, a typical creep failure occurred in the SAC solder joints.

\section{Simulations}

Figure 12 presents the representative creep energy $W_{\text {rce }}$ as a function of flange length for different solder thicknesses. A common trend can be seen: the thinner the solder layer, the higher the representative creep energy $W_{\text {rce }}$ for both flange materials. For a CuMo flange, being more rigid and having a bigger CTE difference from the baseplate, the $W_{\text {rce }}$ values were found to be in the order of a decade higher than these of a $\mathrm{Cu}$ flange.

In Figure $12 \mathrm{~b}$ ) the simulated $W_{\text {rce }}$ for $\mathrm{Cu}$ flange using $\mathrm{SnAg}$ Anand parameters are shown with unbroken lines. In addition, $\mathrm{Cu}$ flange was simulated with SAC305 parameters for solder thicknesses of $56 \mu \mathrm{m}$ and $250 \mu \mathrm{m}$, shown with broken lines. As seen, the simulated $W_{r c e}$ values for SAC305 solder are slightly higher than those simulated with SnAg solder Anand parameters. However, the simulated $W_{r c e}$ values are not directly comparable for solders with different compositions. This is because the thermomechanical properties of different solder compositions may vary, i.e. the preconditions required for crack initiation and propagation can be different. In addition, the potentially different metallurgical reactions with the pad/electrode materials, also affecting in the solidification structure, are not considered in the simulations. So, although the modules with a $\mathrm{CuMo}$ or $\mathrm{Cu}$ flange were attached with different lead-free solder compositions, the observed dissimilarity in cracking behavior is a result of the significant difference in flange material rigidities and in the flanges' CTE mismatch to the AlSi10Mg baseplate, rather than of the use of different solder compositions.

As seen in Figure $12 \mathrm{~b}$ ) for a Cu flange, $W_{r c e}$ seems to saturate as the flange length increases. For a CuMo flange, Figure 12 a), the same kind of behavior can be recognized. To study this behavior closer, the residual stress state on the solder was investigated in more detail, Figure 13 and Figure 14. In the Figure 13, the shear stress between baseplate and both CuMo and $\mathrm{Cu}$ flange is presented as a function of the distance from the neutral plane at varying temperatures from the cold end to the hot end (from 15 to $95^{\circ} \mathrm{C}$ in $10 \mathrm{~min}$ ) for long flange. When the temperature increases, the baseplate starts to dilate faster than the flange, and the shear stress starts to decrease beginning from the farthest end of the neutral plane, i.e. at the flange end. At the light blue line, situated at the end of the broken arrow line, the temperature has reached its upper extreme value. Simultaneously, the absolute value of the stress level has decreased because of solder creep. This is more clearly seen for CuMo flange, Figure 13 a), because the stress levels are higher and the resulting strain and creep much larger compared to $\mathrm{Cu}$ flange, Figure $13 \mathrm{~b}$ ). In the case of long flange, for $\mathrm{CuMo}$ flange, the shear stress exists almost over the whole flange length whereas for $\mathrm{Cu}$ flange the stress is close to zero for a notably long distance from the neutral plane.

In Figure 14 the simulated shear stress between the baseplate and a) a CuMo flange and b) a $\mathrm{Cu}$ flange, at the temperature

Copyright @ 2019 IEEE. Personal use of this material is permitted. However, permission to use this material for any other purposes must be obtained by sending a request to pubs-permissions@ieee.org 
profile's cold and hot ends are presented with different flange lengths. For CuMo flange, Figure 14 a), up to flange length 25.8 $\mathrm{mm}$, the effective shear stress exists almost over the whole flange length, and $W_{\text {rce }}$ increases almost linearly as a function of flange length, Figure 12 a). For longer flanges, the shear stress closer to the neutral plane decreases. As a result, the deformation due to solder creep at the end of the flange is no more increasing linearly as a function of flange length resulting in $W_{\text {rce }}$ no more increasing linearly but showing saturation behavior instead. For a $\mathrm{Cu}$ flange this behavior is different because $\mathrm{Cu}$ flange is less rigid and its CTE is closer to that of the solder and baseplate, compared to CuMo flange. Therefore, with a $\mathrm{Cu}$ flange, the solder layer only deforms considerably closer to the end of the flange, as seen in Figure 14 b), which shows the shear stress between baseplate and $\mathrm{Cu}$ flange at the cold and hot temperature ends. For the shortest flanges, some deformation also exists close to the symmetry plane. With longer flange lengths, this movement becomes limited, resulting in $W_{\text {rce }}$ showing somewhat stronger saturation effect compared to the CuMo flange, as seen in Figure 12.

Figure 15 presents the effect of solder thickness on $W_{\text {rce }}$ for a long PA module with both $\mathrm{CuMo}$ and $\mathrm{Cu}$ flange materials. An inverse, non-linear relationship between $W_{\text {rce }}$ and solder layer thickness can be observed. For thinner solder layer thicknesses, the $W_{\text {rce }}$ values increases due to higher shear strain when the solder thickness decreases.

\section{CONCLUSIONS}

In this work, the reliability of PA modules' flange interconnections for base transceiver station (BTS) applications was investigated by conducting thermal cycling tests (TCT), characterizing interconnections by means of different imaging methods, and by FE modeling dissipated creep energy densities in the solder layer of different assemblies. Simulations of the representative creep energies $\left(W_{r c e}\right)$ show significant differences between the different flange materials and geometric combinations.

The following conclusions can be drawn:

1) Introduction of $\mathrm{Cu}$ flanges in PA modules greatly reduces thermal stress-induced plastic work in the solder, indicating a higher lifetime expectation in field use compared with CuMo flanges. This was due to a low global thermal mismatch and stable as-soldered microstructure that resisted the accumulation of inelastic strain. Thus, recrystallization and formation of a subsequent intergranular creep failure did not occur.

2) The extremely large global thermal mismatch between CuMo flange and the baseplate together with the adverse off-eutectic as-soldered microstructure of the SAC solder joints made them prone to recrystallization. After the formation of a recrystallized microstructure, a typical creep failure occurred in the SAC solder joints. This behavior resulted in a poor creep resistance and reduced lifetime expectations.

3) Simulations showed that increasing the solder thickness results in clearly smaller $W_{\text {rce }}$, suggesting higher reliability.
The use of 96.5/3.5 SnAg solder in the simulations of $\mathrm{Cu}$ flange configurations showed slightly reduced $W_{\text {rce }}$ in the interconnections in TCT, thus suggesting better thermomechanical reliability compared with 96.5/3.0/0.5 $\mathrm{SnAgCu}$ solder. However, the differences in the simulation results are non-significant compared with other, e.g., metallurgical, aspects that affect reliability.

\section{REFERENCES}

[1] N.M. Vichare and M.G. Pecht, "Prognostics and Health Management of Electronics," IEEE Transactions on Components and Packaging Technologies, vol. 29, no. 1, pp. 222-229, 2006. DOI: 10.1109/TCAPT.2006.

[2] D. Kwon, M.H. Azarian, and M. Pecht, "Early Detection of Interconnect Degradation by Continuous Monitoring of RF Impedance," IEEE Transactions on Device and Materials Reliability, vol. 9, no. 2, pp. 296304, 2009. DOI: 10.1109/TDMR.2009.2020170.

[3] J. Putaala, O. Nousiainen, M. Komulainen, T. Kangasvieri, H. Jantunen, and M. Moilanen, "Influence of Thermal-Cycling-Induced Failures on the RF Performance of Ceramic Antenna Assemblies," IEEE Transactions on Components, Packaging and Manufacturing Technology, vol. 1, no. 9, pp. 1465-1472, 2011. DOI: 10.1109/TCPMT.2011.2110655.

[4] P. Lall, R. Lowe, and K. Goebel, "Prognostics Health Management of Electronic Systems Under Mechanical Shock and Vibration Using Kalman Filter Models and Metrics," IEEE Transactions on Industrial Electronics, vol. 59, no. 11, pp. 4301-4314, 2012. DOI: 10.1109/TIE.2012.2183834

[5] J. Lutz, H. Schlangenotto, U. Scheuermann, and R. De Doncker, "Packaging and Reliability of Power Devices," in Semiconductor Power Devices: Physics, Characteristics, Reliability, Springer, 1st ed. Heidelberg (Germany), 2011, ch. 11, pp. 403-404.

[6] IPC-9701 Standard: Performance Test Methods and Qualification Requirements for Surface Mount Solder Attachments, Institute of Printed Circuits, 2002.

[7] JEDEC Standard JESD22-A104D: Temperature Cycling, JEDEC Solid State Technology Association, 2009.

[8] J.E. Semmens and L.W. Kessler, "Characterization of flip chip interconnect failure modes using high frequency acoustic micro imaging with correlative analysis," in Proceedings of the 1997 35th Annual IEEE International Reliability Physics Symposium, DOI: 10.1109/RELPHY.1997.584251, 8 April - 10 April 1997, pp. 141-148, 1997.

[9] L. Anand, "Constitutive Equations for the Rate-Dependent Deformation of Metals at Elevated Temperatures," Journal of Engineering Materials and Technology, vol. 104, no. 1, pp. 12-17, 1982. DOI: 10.1115/1.3225028.

[10] M. Motalab, Z. Cai, J.C. Suhling, J. Zhang, J.L. Evans, M.J. Bozack, and P. Lall, "Improved Predictions of Lead Free Solder Joint Reliability that Include Aging Effects," in Proceedings of the 62nd IEEE Electronic Components and Technology Conference, DOI: 10.1109/ECTC.2012.6248879, pp. 513-531, 2012.

[11] Z.N. Cheng, G.Z. Wang, L. Chen, J. Wilde, and K. Becker, "Viscoplastic Anand model for solder alloys and its application," Soldering \& Surface Mount Tech, vol. 12, no. 2, pp. 31-36, 2000. DOI: 10.1108/09540910010331428.

[12] E-business center of China Tungsten Industry Association, (CTIA), Copper Molybdenum sheet, Mo70Cu30 heat sinks, Available: http://www.tungstencopper.net/Mo70Cu30-heat-sinks/default.htm. Accessed on: Aug. 15th, 2018.

[13] J.J. Sundelin, S.T. Nurmi, and T.K. Lepistö, "Recrystallization behaviour of SnAgCu solder joints," Materials Science and Engineering: A, vol. 474, no. 1, pp. 201-207, 2008. DOI: 10.1016/j.msea.2007.04.013.

[14] O. Nousiainen, T. Kangasvieri, R. Rautioaho, and J. Vähäkangas, "Thermal fatigue endurance of $\operatorname{Sn} 3 \mathrm{Ag} 0.5 \mathrm{Cu} 0.5 \mathrm{In} 0.05 \mathrm{Ni}$ and $\mathrm{Sn} 2.5 \mathrm{Ag} 0.8 \mathrm{Cu} 0.5 \mathrm{Sb}$ solders in composite solder joints of LTCC/PWB assemblies," Soldering \& Surface Mount Technology, vol. 23, no. 1, pp. 30-39, 2011. DOI: 10.1108/09540911111099686.

[15] J. Pan, J. Silk, M. Powers, and P. Hyland, "Effect of Gold Content on the Reliability of $\mathrm{SnAgCu}$ Solder Joints," IEEE Transactions on Components, Packaging and Manufacturing Technology, vol. 1, no. 10, pp. 1662-1669, 2011. DOI: 10.1109/TCPMT.2011.2160398. 
[16] S. Yang, Y. Tian, and C. Wang, "Investigation on Sn grain number and crystal orientation in the $\mathrm{Sn}-\mathrm{Ag}-\mathrm{Cu} / \mathrm{Cu}$ solder joints of different sizes," Journal of Materials Science: Materials in Electronics, vol. 21, no. 11, pp. 1174-1180, 2010. DOI: 10.1007/s10854-009-0042-x.

[17] A. LaLonde, D. Emelander, J. Jeannette, C. Larson, W. Rietz, D. Swenson, and D.W. Henderson, "Quantitative metallography of $\beta$-Sn dendrites in $\mathrm{Sn}-3.8 \mathrm{Ag}-0.7 \mathrm{Cu}$ ball grid array solder balls via electron backscatter diffraction and polarized light microscopy," Journal of Electronic Materials, vol. 33, no. 12, pp. 1545-1549, 2004. DOI: 10.1007/s11664004-0096-8.

[18] M. Berthou, P. Retailleau, H. Frémont, A. Guédon-Gracia, and C. JéphosDavennel, "Microstructure evolution observation for SAC solder joint: Comparison between thermal cycling and thermal storage," Microelectronics Reliability, vol. 49, no. 9, pp. 1267-1272, 2009. DOI: 10.1016/j.microrel.2009.07.040.

[19] S. Terashima, K. Takahama, M. Nozaki, and M. Tanaka, "Recrystallization of Sn Grains due to Thermal Strain in Sn-1.2Ag-0.5Cu0.05Ni Solder," Materials Transactions, vol. 45, no. 4, pp. 1383-1390, 2004. DOI: $10.2320 /$ matertrans.45.1383.

[20] D.W. Hendersson, J.J. Woods, T.A. Gosselin, J. Bartelo, D.E. King, T.M. Korhonen, M.A. Korhonen, L.P. Lehman, E.J. Cotts, S.K. Kang, P. Lauro, D. Shih, C. Goldsmith, and K.J. Puttliz, "The microstructure of Sn in neareutectic $\mathrm{Sn}-\mathrm{Ag}-\mathrm{Cu}$ alloy solder joints and its role in thermomechanical fatigue," Journal of Materials Research, vol. 19, no. 6, pp. 1608-1612, 2004. DOI: 10.1557/JMR.2004.0222.

[21] T.T. Mattila, V. Vuorinen, and J.K. Kivilahti, "Impact of printed wiring board coatings on the reliability of lead-free chip-scale package interconnections," Journal of Materials Research, vol. 19, no. 11, pp. 3214-3223, 2004. DOI: 10.1557/JMR.2004.0436.

[22] M.A. Matin, W.P. Vellinga, and M.G.D. Geers, "Microstructure evolution in a $\mathrm{Pb}$-free solder alloy during mechanical fatigue," Materials Science and Engineering: A, vol. 431, no. 1, pp. 166-174, 2006. DOI: 10.1016/j.msea.2006.05.144.

[23] T.K. Korhonen, L.P. Lehman, M.A. Korhonen, and D.W. Henderson, "Isothermal Fatigue Behavior of the Near-Eutectic Sn-Ag-Cu Alloy between $-25^{\circ} \mathrm{C}$ and $125^{\circ} \mathrm{C}$," Journal of Electronic Materials, vol. 36, no. 2, pp. 173-178, 2007. DOI: 10.1007/s11664-006-0048-6.

[24] M.A. Matin, W.P. Vellinga, and M.G.D. Geers, "Thermomechanical fatigue damage evolution in SAC solder joints," Materials Science \& Engineering $A$, vol. 445, no. 1, pp. 73-85, 2007. DOI: 10.1016/j.msea.2006.09.037.

[25] S. Park, R. Dhakal, L. Lehman, and E. Cotts, "Measurement of deformations in $\mathrm{SnAgCu}$ solder interconnects under in situ thermal loading," Acta Materialia, vol. 55, no. 9, pp. 3253-3260, 2007. DOI: 10.1016/j.actamat.2007.01.028

[26] J. Hokka, T.T. Mattila, H. Xu, and M. Paulasto-Kröckel, "Thermal Cycling Reliability of Sn-Ag-Cu Solder Interconnections. Part 1: Effects of Test Parameters," Journal of Electronic Materials, vol. 42, no. 6, pp. 1171-1183, 2013. DOI: 10.1007/s11664-013-2551-x.

[27] J. Hokka, T.T. Mattila, H. Xu, and M. Paulasto-Kröckel, "Thermal Cycling Reliability of Sn-Ag-Cu Solder Interconnections. Part 2: Failure Mechanisms," Journal of Electronic Materials, vol. 42, no. 6, pp. 963972, 2013. DOI: 10.1007/s11664-013-2475-5.

[28] O. Nousiainen, L. Lehtiniemi, T. Kangasvieri, R. Rautioaho, and J. Vähäkangas, "Thermal fatigue endurance of collapsible $95.5 \mathrm{Sn} 4 \mathrm{Ag} 0.5 \mathrm{Cu}$ spheres in LTCC/PWB assemblies," Microelectronics Reliability, vol. 48, no. 4, pp. 622-630, 2008. DOI: 10.1016/j.microrel.2007.11.001.

[29] O. Nousiainen, T. Urhonen, T. Kangasvieri, R. Rautioaho, and J. Vähäkangas, "Thermomechanically loaded lead-free LGA joints in LTCC/PWB assemblies," Soldering \& Surface Mount Technology, vol. 22, no. 2, pp. 21-29, 2010. DOI: 10.1108/09540911011036253.

[30] O. Nousiainen, O. Salmela, J. Putaala, and T. Kangasvieri, "Enhanced thermal fatigue endurance and lifetime prediction of lead-free LGA joints in LTCC modules," Soldering \& Surface Mount Technology, vol. 23, no. 2, pp. 104-114, 2011. DOI: 10.1108/09540911111120177.

[31] H.Y. Lu, H. Balkan, and K.Y.S. Ng, "Effect of $\mathrm{Ag}$ content on the microstructure development of Sn-Ag-Cu interconnects," Journal of Materials Science: Materials in Electronics, vol. 17, no. 3, pp. 171-178, 2006. DOI: $10.1007 / \mathrm{s} 10854-006-6758-y$.

[32] S. Terashima, Y. Kariya, T. Hosoi, and M. Tanaka, "Effect of silver content on thermal fatigue life of $\mathrm{Sn}-\mathrm{xAg}-0.5 \mathrm{Cu}$ flip-chip interconnects," Journal of Electronic Materials, vol. 32, no. 12, pp. 1527-1533, 2003. DOI: $10.1007 / \mathrm{s} 11664-003-0125-\mathrm{z}$.
[33] J.S. Hwang, "Environment-friendly Electronics: Lead-free Technology", Emerald, 2002.

Copyright $\odot 2019$ IEEE. Personal use of this material is permitted. However, permission to use this material for any other purposes must be obtained by sending a request to pubs-permissions@ieee.org 